Quim. Nova, Vol. 29, No. 1, 28-33, 2006

\title{
ESTUDO DOS EFEITOS DO SILÍCIO E DO FÓSFORO NA REDUÇÃO DA DISPONIBILIDADE DE METAIS PESADOS EM ÁREA DE MINERAÇÃOO
}

\author{
Lilian Aparecida Paim*, Ruy Carvalho, Celeste Maria Patto Abreu e Mário César Guerreiro \\ Departamento de Química, Universidade Federal de Lavras, CP 37, 37200-000, Lavras - MG
}

Recebido em 24/9/04; aceito em 20/4/05; publicado na web em 8/9/05

\begin{abstract}
STUDY OF EFFECTS OF SILICON AND PHOSPHORUS IN REDUCING THE AVAILABILITY OF HEAVY METALS IN MINING AREA. This study was developed with a soil contaminated by heavy metals, with the purpose of evaluating the action of silicon and phosphorus as protection agents through simple extractions by DTPA. The collected samples were prepared and incubated with five doses of silicon and five doses of phosphorus, with four replicates, amounting to 100 experimental units. After 30 and 60 days, samples of each treatment were collected, submitted to $\mathrm{pH}$ analyses and simple extraction by DTPA. The amounts of DTPAextracted metals depended on the doses of silicon and phosphorus and on the $\mathrm{pH}$. Treatments with silicon and phosphorus was efficient in decreasing the availability of heavy metals in soil.
\end{abstract}

Keywords: silicon; phosphorus; heavy metals.

\section{INTRODUÇÃO}

O ser humano exerce grande influência sobre o meio ambiente. Enquanto as alterações geológicas e biológicas sobre a superfície da terra são vagarosas, as mudanças introduzidas ou estimuladas pelo homem têm sido extremamente rápidas e acumulativas nos últimos anos. No município de Três Marias-MG, uma área de 18 ha encontra-se em avançado processo de degradação ambiental ${ }^{1}$ causado pelo despejo de dejetos industriais na superfície do solo, provenientes da mineração e industrialização de zinco. A contaminação deve-se não apenas ao $\mathrm{Zn}$ residual da mineração, mas também a outros metais, como $\mathrm{Cd}, \mathrm{Pb}$ e $\mathrm{Cu}$, presentes no minério de $\mathrm{Zn}$ ou empregados no processamento industrial do mesmo. Esses metais, notadamente $\mathrm{Cd}$ e $\mathrm{Pb}$ que não apresentam quaisquer benefícios ao organismo humano ${ }^{2}$, encontram-se em teores superiores àqueles permitidos para solos e tolerados pelos seres vivos ${ }^{3,4}$. Constituem, portanto, um obstáculo à revegetação da área e uma ameaça a todos os outros componentes do ecossistema.

A aplicação ao solo de substâncias básicas como carbonatos $\left(\mathrm{CO}_{3}^{-2}\right)$, silicatos $\left(\mathrm{SiO}_{3}^{-2}\right)$ e agentes complexantes, esses últimos presentes no material orgânico (restos vegetais), constituem importantes medidas amenizadoras da contaminação do solo por metais pesados ${ }^{5}$. Os ânions $\mathrm{SiO}_{3}^{-2}$, presentes no silicato de cálcio $\left(\mathrm{CaSiO}_{3}\right)$, à semelhança do $\mathrm{CO}_{3}^{-2}$, combinam-se com os íons $\mathrm{H}^{+}$ disponíveis na solução do solo $^{6}$ aumentando o $\mathrm{pH}$ e diminuindo a atividade química (mobilidade em água, adsorção às partículas coloidais e absorção pelas plantas) por precipitação dos metais na forma de hidróxidos ${ }^{5,7}$. Como benefício adicional muito importante e vantajoso em relação aos calcários, a incorporação de $\mathrm{CaSiO}_{3}$, principalmente em doses elevadas, promove a polimerização de compostos silicatados, potenciais ligantes para a formação de complexos insolúveis com os metais pesados ${ }^{8,9}$.

$\mathrm{O}$ ânion di-hidrogenofosfato $\left(\mathrm{H}_{2} \mathrm{PO}_{4}^{-}\right)$, devido a sua capacidade de formar sais e complexos pouco solúveis de $\mathrm{Zn}, \mathrm{Cu}, \mathrm{Pb}$ e $\mathrm{Cd}^{10,11}$, diminui a disponibilidade dos mesmos no solo, além de fornecer fósforo a essas áreas normalmente pobres neste e em outros elementos úteis às plantas no caso de uma revegetação.

*e-mail: lilianbarone@bol.com.br
São poucas as pesquisas sobre o aproveitamento do silício originado de silicatos como corretivo em solos contaminados por metais pesados, isolado ou associado ao fósforo, e sobre a aparente viabilidade econômica do emprego do silício advindo das escórias de siderurgia, ricas em silicato de cálcio. Assim, este trabalho teve por objetivo avaliar a eficiência combinada do silício e do fósforo na disponibilidade de $\mathrm{Zn}, \mathrm{Cu}, \mathrm{Pb}$ e $\mathrm{Cd}$, por meio de extrações simples com ácido dietilenotriaminopentaacético (DTPA), um complexante de uso rotineiro nas determinações de elementos de transição $(\mathrm{Zn}, \mathrm{Cu}, \mathrm{Mn}, \mathrm{Fe})$ essenciais às plantas em solos agrícolas e que vem sendo adaptado ao estudo dos metais pesados ${ }^{12,13}$.

\section{PARTE EXPERIMENTAL}

\section{Caracterização do solo}

Foram estudados solos contaminados por metais pesados, provenientes de uma área de rejeitos da unidade de extração e industrialização de zinco no município de Três Marias-MG.

As amostras de solo coletadas, após secagem ao ar, foram passadas em peneira de $2 \mathrm{~mm}$ de diâmetro. As análises químicas do solo contaminado podem ser encontradas na Tabela 1 . O pH foi determinado na relação 1:2,5 (solo:água) por leituras potenciométricas; $\mathrm{Ca}^{2+}$ e $\mathrm{Mg}^{2+}$ trocáveis foram extraídos com $\mathrm{KCl}$ $1 \mathrm{~mol} \mathrm{~L}^{-1} \mathrm{e}$ analisados por titulometria ${ }^{14} ; \mathrm{H}_{2} \mathrm{PO}_{4}^{-}$e $\mathrm{K}^{+}$disponíveis foram obtidos com extrator Mehlich-1 $\left(\mathrm{HCl} \mathrm{0,05} \mathrm{mol} \mathrm{L}{ }^{-1}+\mathrm{H}_{2} \mathrm{SO}_{4}\right.$ $\left.0,0125 \mathrm{~mol} \mathrm{~L}^{-1}\right)$ e determinados, respectivamente, por colorimetria e fotometria de chama ${ }^{14,15}$. A acidez potencial $\left(\mathrm{H}^{+}+\mathrm{Al}^{3+}\right)$ foi determinada de forma indireta, por meio de solução Schomacker-McleanPratt (SMP) $\left(\mathrm{CaCl}_{2} \cdot \mathrm{H}_{2} \mathrm{O}+\mathrm{K}_{2} \mathrm{CrO}_{4}+\mathrm{CaC}_{2} \mathrm{O}_{4}+\right.$ trietanolamina, corrigido a $\mathrm{pH} 7,5)^{16}$. O carbono orgânico foi determinado pelo método colorimétrico por digestão com bicromato de sódio, conforme Raij et al. ${ }^{17}$. Os teores de óxidos de Fe pedogênicos foram obtidos através de extrações sucessivas com ditionito-citrato-bicarbonato de sódio (DCB) $)^{18,19}$, os teores de Fe, Si, Al, Ti e P expressos na forma de óxidos foram determinados da digestão sulfúrica, de acordo com metodologia descrita por Vettori ${ }^{15}$ e a capacidade máxima de adsorção de fósforo (CMAF) estimada segundo Syers et al. ${ }^{20}$. 


\section{Realização do experimento}

$\mathrm{Na}$ realização da pesquisa, cada unidade experimental constou de um frasco de polietileno com capacidade para $7 \mathrm{dm}^{3}$, ocupado com $3,8 \mathrm{dm}^{3}$ de solo passado em peneira de $2 \mathrm{~mm}$ de diâmetro. Todas as amostras foram submetidas à incubação após serem tratadas com doses de silício combinadas com doses de fósforo por um período total de 60 dias, sob nível de umidade equivalente a $20 \%$ do volume de solo utilizado em cada frasco ${ }^{21}$. As doses de silício, a partir do silicato de cálcio $\left(\mathrm{CaSiO}_{3}\right.$ p.a. Vetec, $29 \%$ de Si e 13,21\% de Ca) correspondentes a 0; 2340; 6040; 9860 e $13660 \mathrm{mg} \mathrm{dm}^{-3}$ de $\mathrm{Si}$, foram estabelecidas por equação de regressão construída a partir de um experimento prévio de incubação do solo contaminado seco ao ar em copos de polietileno. Para obtenção da equação incubaram-se $200 \mathrm{~g}$ de solo com dez doses crescentes de silicato de cálcio $(0 ; 100 ; 200 ; 400,500 ; 800 ; 1600$; 2000; 4000 e 5000 mg) em três repetições, totalizando 30 copos de polietileno, mantidos com teor de umidade equivalente a $20 \%$ do peso de solo em cada copo. Foram feitas leituras de $\mathrm{pH}$ no sobrenadante da mistura solo: água $(1: 2,5)$, após agitação da mesma com um bastão de vidro por $5 \mathrm{~min}$ e repouso de $30 \mathrm{~min}$. Através da equação $\mathrm{Y}=0,1902 \mathrm{X}+4,7076(\mathrm{Y}=\mathrm{pH}$ e $\mathrm{X}=$ doses de $\mathrm{Si})$ calcularam-se as cinco doses de $\mathrm{Si}$ necessárias para obter os valores de pH 4,6 (solo virgem, sem adição de Si); 5,0; 5,5; 6,0 e 6,5 .

As doses de fósforo $\left(\mathrm{Ca}\left(\mathrm{H}_{2} \mathrm{PO}_{4}\right)_{2} \cdot \mathrm{H}_{2} \mathrm{O}\right.$ p.a. Fluka) foram $0 ; 90$; 180; 360 e $720 \mathrm{mg} \mathrm{dm}^{-3}$ de $\mathrm{P}$, deduzidas da isoterma de Langmuir, esta obtida de experimento prévio para determinação da capacidade máxima de adsorção de fósforo (CMAF) $)^{15}$. A dose central (180 $\mathrm{mg} \mathrm{dm}{ }^{-3} \mathrm{de} \mathrm{P}$ ) corresponde ao teor necessário para manter $0,2 \mathrm{mg}$ $\mathrm{dm}^{-3}$ de fósforo na solução do solo, suficiente para nutrir a maioria das plantas cultivadas ${ }^{22}$

Como as fontes de silício e fósforo empregadas foram sais de cálcio, procedeu-se a um ajuste do teor do mesmo nas amostras pela adição de cloreto de cálcio $\left(\mathrm{CaCl}_{2} \cdot 2 \mathrm{H}_{2} \mathrm{O}\right.$ p.a. Reagen $)$.

$\mathrm{O}$ delineamento experimental utilizado foi de forma casual, arranjado num fatorial de 5 x 5 (cinco doses de silício e cinco de fósforo), perfazendo 25 tratamentos com quatro repetições, totalizando 100 unidades experimentais.

\section{Avaliação do experimento}

Análise de pH em água

Após um período de 30 e 60 dias da aplicação das doses, foram transferidos, de cada tratamento, $10 \mathrm{~cm}^{3}$ de terra fina seca ao ar (TFSA) para copos plásticos, juntamente com $25 \mathrm{~mL}$ de água destilada (1:2,5). Agitou-se, com um bastão de vidro, por $30 \mathrm{~s}$, deixando em repouso por $1 \mathrm{~h}$ antes de realizar as leituras potenciométricas.

\section{Extração com DTPA}

Após um período de 30 e 60 dias da aplicação das doses, foram transferidos, de cada tratamento, $10 \mathrm{mg}$ de terra fina seca em estufa por $48 \mathrm{~h}\left(\mathrm{TFSE}-105^{\circ} \mathrm{C}\right)$ para frascos de vidro, adicionando-se $50 \mathrm{~mL}$ da solução extratora (DTPA $0,005 \mathrm{~mol} \mathrm{~L}^{-1}+$ trietanolamina $0,1 \mathrm{~mol} \mathrm{~L}^{-1}+$ cloreto de cálcio $0,01 \mathrm{~mol} \mathrm{~L}^{-1}+5$ $\mathrm{mL}$ de $\mathrm{HCl}$ e corrigido a $\mathrm{pH} 7,3)^{23}$. Após agitação mecânica (velocidade de $240 \mathrm{rpm}$ ) por $2 \mathrm{~h}$ seguida de filtração quantitativa dos extratos, procedeu-se à análise em um espectrômetro de absorção atômica de chama, Carl Zeiss Jena AAS4, com chama de gás acetileno e lâmpada de cátodo oco: $\mathrm{Cd}(228,8 \mathrm{~nm}$, fenda 0,5$) ; \mathrm{Pb}$ $(217,0 \mathrm{~nm}$, fenda 1,0); Cu (324,8 nm, fenda 0,5) e Zn $(213,9 \mathrm{~nm}$, fenda 0,5$)$.

\section{Tratamento estatístico}

Os dados obtidos ( $\mathrm{pH}$ e teores de $\mathrm{Pb}, \mathrm{Cd}, \mathrm{Cu}$ e $\mathrm{Zn}$ ) foram submetidos à análise de variância, utilizando-se o programa Sanest ${ }^{24}$. Concluída a análise de variância foram ajustadas equações de regressão polinomial (aplicativo Sigma Plot), para as variáveis experimentais $\mathrm{pH}, \mathrm{Pb}, \mathrm{Cd}, \mathrm{Cu}$, e $\mathrm{Zn}$, aos 30 e 60 dias, em função das doses de silício e de fósforo.

\section{RESULTADOS E DISCUSSÃO}

\section{Influência das doses de silício e de fósforo no comportamento do $\mathbf{p H}$}

Observou-se um aumento do pH em função das doses crescentes de silício e fósforo, revelando um comportamento semelhante do pH após 30 e 60 dias da aplicação (Figura 1). Os valores máximos de pH, 7,5 após 30 dias e 8,0 após 60 dias (Figura 1), ocorreram para aplicações de $8030 \mathrm{mg} \mathrm{dm}^{-3}$ de silício. Em relação ao silício, o aumento do $\mathrm{pH}$ deve-se aos ânions $\mathrm{SiO}_{3}^{-2}$ que atuam como bases de Bronsted-Lowry, capturando prótons $\mathrm{H}^{+}$(acidez) dissolvidos na água do solo. Já o papel do fósforo na mudança do $\mathrm{pH}$ pode ser entendido de duas formas. Primeiro, por reação química de precipitação do ânion fosfato diácido $\left(\mathrm{H}_{2} \mathrm{PO}_{4}^{-}\right.$) com os íons $\mathrm{Cd}^{+2}, \mathrm{Zn}^{+2}, \mathrm{Cu}^{+2}$ ou $\mathrm{Pb}^{+2}$, os quais (ácidos de Lewis) ${ }^{25}$ antes da aplicação do fósforo eram os principais responsáveis pela elevada acidez das amostras de campo (Tabela 1). Segundo, pela própria combinação dos íons $\mathrm{H}_{2} \mathrm{PO}_{4}^{-}$com as superfícies dos minerais de argila (óxidos de $\mathrm{Fe}$ e Al) presentes no solo (Tabela 1), um processo de troca de ligantes do complexo de superfície em que hidroxilas $\left(\mathrm{OH}^{-}\right)$previamente coordenadas aos cátions $\mathrm{Fe}^{+3}$ ou $\mathrm{Al}^{+3}$ são deslocadas pelos íons $\mathrm{H}_{2} \mathrm{PO}_{4}$, formando um novo complexo de superfície ${ }^{26,27}$.

A diminuição de $\mathrm{pH}$, de aproximadamente 7,5 para 6,0 (Figura 1), foi observada para doses elevadas de silício (>8030 mg $\mathrm{dm}^{-3}$ ), o que sugere uma diminuição da atividade dos ânions $\mathrm{SiO}_{3}^{-2}$, como bases e um aumento de sua participação como polímeros de Si atuando como ligantes para formação de complexos insolúveis dos metais ${ }^{9,23}$. A química do $\mathrm{Si}^{8}$ mostra que a espécie $\mathrm{H}_{2} \mathrm{SiO}_{3}$ (ácido metassilícico) resultante da captura de dois prótons $\mathrm{H}^{+}$não se estabiliza como tal, tendendo a combinar-se com $\mathrm{H}_{2} \mathrm{O}$ para formar o hidroxiácido $\mathrm{Si}(\mathrm{OH})_{4}$ (ácido monossilícico) (ou $\mathrm{H}_{4} \mathrm{SiO}_{4}$ ). Doses maiores que $100 \mathrm{mg} \mathrm{dm}^{-3} \mathrm{de} \mathrm{Si}$ mudam parte da coordenação do elemento de quatro para seis, no íon complexo $\left[\mathrm{Si}(\mathrm{OH})_{5} \mathrm{H}_{2} \mathrm{O}\right]^{\prime}$, ponto de partida para a polimerização. Dímeros do tipo $\left[\mathrm{Si}_{2} \mathrm{O}_{3}(\mathrm{OH})_{4}\right]^{-2}$ até polímeros com mais de dez átomos de $\mathrm{Si}$, descritos por Dietzel $^{9}$, combinam-se facilmente com os metais pesados. De fato, quando houve um aumento brusco da dose de silício de 6040 para $13660 \mathrm{mg} \mathrm{dm}^{-3}$ foi constatada, durante a condução da pesquisa, a presença de corpúsculos esbranquiçados sobre as partículas de solo nos frascos correspondentes às maiores doses de silício.

\section{Teores de chumbo extraídos pelo DTPA, em função das doses de silício e de fósforo}

Para chumbo, de modo geral, aos 30 e 60 dias (Figura 2), houve uma relação direta entre os teores extraídos pelo DTPA, para doses de silício e para as de fósforo. O máximo extraído aos 30 dias, cerca de $5 \mathrm{mg} \mathrm{dm}^{-3} \mathrm{de} \mathrm{Pb}$, à semelhança do que ocorreu com o $\mathrm{pH}$ em torno de 7,5 (Figura 1), corresponde à dose $7623 \mathrm{mg} \mathrm{dm}^{-3}$ de silício. Isto indica que a formação do quelato estável Pb-DTPA $(\log \mathrm{k}=18,6)^{28}$, condição necessária ao bom funcionamento do extrator, depende do $\mathrm{pH}$. Este diminuiu mais de 50\% com a dose $13660 \mathrm{mg} \mathrm{dm}^{-3}$ de silício 

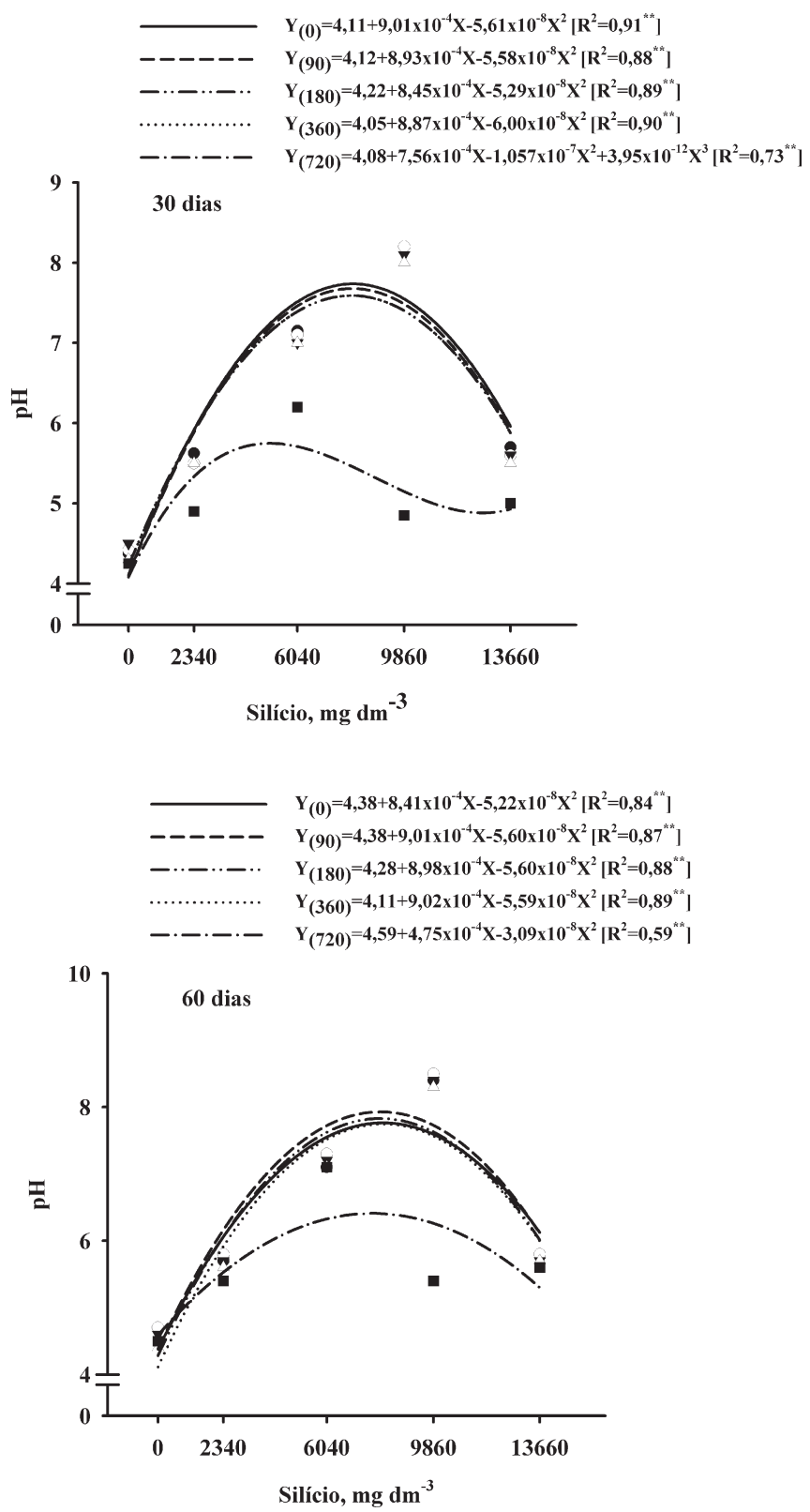

Figura 1. Efeito das doses de silício e de fósforo $\left(\mathrm{mg} \mathrm{dm}^{-3}\right)$ no comportamento do $\mathrm{pH}$ do solo contaminado por metais pesados, em diferentes períodos de incubação

na ausência de fósforo e reduziu-se praticamente a zero de extração, aos 30 dias na mesma dose de silício combinada com 90 e $180 \mathrm{mg}$ $\mathrm{dm}^{-3}$ de fósforo (Figura 2). A sobreposição destas duas curvas com aquela referente à dose $0 \mathrm{mg} \mathrm{dm}^{-3}$ de fósforo, aos 30 dias (Figura 2), sugere que o $\mathrm{pH}$, muito mais que o fósforo, foi o principal parâmetro a influir na extração de $\mathrm{Pb}$ pelo DTPA. A dependência de $\mathrm{pH}$ ficou comprovada quando o mesmo teor de $\mathrm{Pb}$ extraído aos 30 dias repetiu-se aos 60 dias após a dosagem. Porém, neste caso, com a dose $6481 \mathrm{mg} \mathrm{dm}^{-3}$ de silício e $0 \mathrm{mg} \mathrm{dm}^{-3}$ de fósforo, sem sobreposição da curva de zero de fósforo.

$\mathrm{O}$ fato da estabilidade do quelato Pb-DTPA depender ou não do $\mathrm{pH}$ parece relacionar-se com o tempo de alcance do equilíbrio na reação de formação do complexo. É razoável admitir que, aos 30 e 60 dias, como a quantidade de $\mathrm{Pb}$ ainda era muito alta no solo, a elevação do $\mathrm{pH}$ pelo silício tornou-se necessária para desprotonação dos grupos carboxílicos da molécula do DTPA, li-
Tabela 1. Atributos químicos e mineralógicos do solo contaminado por metais pesados, utilizado nos experimentos

\begin{tabular}{|c|c|}
\hline Atributos & Solo \\
\hline pH em água & 4,6 \\
\hline $\mathrm{P}_{\text {Mehlich-1 }}\left(\mathrm{mg} \mathrm{dm}^{-3}\right)$ & 2,0 \\
\hline $\mathrm{P}_{\text {Resina }}\left(\mathrm{mg} \mathrm{dm}^{-3}\right)$ & 2,6 \\
\hline $\left.\mathrm{K}(\mathrm{mg} \mathrm{dm})^{-3}\right)$ & 51,5 \\
\hline $\mathrm{Ca}\left(\mathrm{cmol}_{\mathrm{c}} \mathrm{dm}^{-3}\right)$ & 4,0 \\
\hline $\mathrm{Mg}\left(\mathrm{cmol}_{\mathrm{c}} \mathrm{dm}^{-3}\right)$ & 6,2 \\
\hline $\mathrm{Al}\left(\mathrm{cmol}_{\mathrm{c}} \mathrm{dm}^{-3}\right)$ & 0,5 \\
\hline $\mathrm{H}^{+}+\mathrm{Al}^{+{ }^{\mathrm{c}}}\left(\mathrm{cmol}_{\mathrm{c}} \mathrm{dm}^{-3}\right)$ & 5,6 \\
\hline $\mathrm{S}\left(\mathrm{mg} \mathrm{dm}^{-3}\right)$ & $1.313,4$ \\
\hline $\mathrm{t}\left(\mathrm{cmol}_{\mathrm{c}} \mathrm{dm}^{-3}\right)$ & 10,8 \\
\hline $\mathrm{T}\left(\mathrm{cmol}_{\mathrm{c}} \mathrm{dm}^{-3}\right)$ & 15,9 \\
\hline $\mathrm{m}(\%)$ & 4,6 \\
\hline $\mathrm{V}(\%)$ & 64,8 \\
\hline Carbono orgânico $\left(\mathrm{g} \mathrm{kg}^{-1}\right)$ & 0,7 \\
\hline $\mathrm{B}\left(\mathrm{mg} \mathrm{dm}^{-3}\right)$ & 0,7 \\
\hline $\mathrm{Zn}_{\text {DTPA }}\left(\mathrm{mg} \mathrm{dm}^{-3}\right)$ & $1.562,5$ \\
\hline $\mathrm{Cu}_{\text {DTPA }}\left(\mathrm{mg} \mathrm{dm}^{-3}\right)$ & 9,0 \\
\hline $\mathrm{Cd}_{\text {DTPA }}\left(\mathrm{mg} \mathrm{dm}^{-3}\right)$ & 25,9 \\
\hline $\mathrm{Pb}_{\text {DTPA }}\left(\mathrm{mg} \mathrm{dm}^{-3}\right)$ & 2,7 \\
\hline $\mathrm{Mn}_{\text {DTPA }}\left(\mathrm{mg} \mathrm{dm}^{-3}\right)$ & 47,5 \\
\hline $\mathrm{Fe}_{\text {DTPA }}\left(\mathrm{mg} \mathrm{dm}^{-3}\right)$ & 0,9 \\
\hline Areia $\left(\mathrm{g} \mathrm{kg}^{-1}\right)$ & 270,0 \\
\hline Silte $\left(\mathrm{g} \mathrm{kg}^{-1}\right)$ & 467,0 \\
\hline Argila $\left(\mathrm{g} \mathrm{kg}^{-1}\right)$ & 262,0 \\
\hline $\mathrm{Fe}_{2} \mathrm{O}_{3} \mathrm{~d}\left(\mathrm{~g} \mathrm{~kg}^{-1}\right)^{1}$ & 86,9 \\
\hline $\mathrm{SiO}_{2}\left(\mathrm{~g} \mathrm{~kg}^{-1}\right)^{2}$ & 169,2 \\
\hline $\mathrm{Al}_{2} \mathrm{O}_{3}\left(\mathrm{~g} \mathrm{~kg}^{-1}\right)^{2}$ & 139,5 \\
\hline $\mathrm{Fe}_{2} \mathrm{O}_{3}\left(\mathrm{~g} \mathrm{~kg}^{-1}\right)^{2}$ & 53,7 \\
\hline $\mathrm{TiO}_{2}\left(\mathrm{~g} \mathrm{~kg}^{-1}\right)^{2}$ & 3,9 \\
\hline $\mathrm{P}_{2} \mathrm{O}_{5}\left(\mathrm{~g} \mathrm{~kg}^{-1}\right)^{2}$ & 0,6 \\
\hline CMAF $\left(\mathrm{mg} \mathrm{kg}^{-1}\right)$ & 635,0 \\
\hline $\mathrm{Ct}\left(\mathrm{g} \mathrm{kg}^{-1}\right)$ & 237,1 \\
\hline $\mathrm{Gb}\left(\mathrm{g} \mathrm{kg}^{-1}\right)$ & 40,4 \\
\hline $\mathrm{Gt} / \mathrm{Gt}+\mathrm{Hm}$ & 0,8 \\
\hline $\mathrm{Hm} / \mathrm{Hm}+\mathrm{Gt}$ & 0,2 \\
\hline
\end{tabular}

${ }^{1} \mathrm{Fe}_{2} \mathrm{O}_{3} \mathrm{~d}=$ ferro ditionito; ${ }^{2}$ óxidos do ataque sulfúrico; $\mathrm{Ct}=$ caulinita; $\mathrm{Gt}=$ goethita; $\mathrm{Hm}=$ hematita, $\mathrm{Gb}=$ gibbisita

berando-os como doadores de elétrons ao $\mathrm{Pb}^{+2}$ no processo de coordenação. As doses 360 e $720 \mathrm{mg} \mathrm{dm}^{-3}$ de fósforo aos 30 e 60 dias (Figura 2) não permitiram ajuste matemático.

\section{Teores de cádmio extraídos pelo DTPA, em função das doses de silício e de fósforo}

Observa-se que para o cádmio, aos 30 e 60 dias (Figura 3), os teores máximos extraídos, cerca de 49 e $35,6 \mathrm{mg} \mathrm{dm}^{-3}$, respectivamente, resultaram da combinação de $1475 \mathrm{mg} \mathrm{dm}^{-3}$ de silício x $360 \mathrm{mg} \mathrm{dm}^{-3}$ de fósforo e $0 \mathrm{mg} \mathrm{dm}^{-3}$ de silício x $360 \mathrm{mg} \mathrm{dm}^{-3}$ de fósforo, coincidindo também com pH em torno de 5,2 e 4,6 (Figura 1). As doses 90 e $180 \mathrm{mg} \mathrm{dm}^{-3}$ de fósforo aos 30 dias e 180 e $360 \mathrm{mg} \mathrm{dm}^{-3}$ de fósforo aos 60 dias também proporcionaram teores de $\mathrm{Cd}$ maiores que a dose 0 $\mathrm{mg} \mathrm{dm}{ }^{-3}$ de fósforo. Infere-se, daí, que o fósforo, muito mais que o $\mathrm{pH}$, cuja elevação deve-se ao silício, influiu na disponibilidade de $\mathrm{Cd}$. Com $9775 \mathrm{mg} \mathrm{dm}^{-3}$ de silício x $360 \mathrm{mg} \mathrm{dm}^{-3}$ de fósforo resultou a menor extração de $\mathrm{Cd}$, cerca de $16,7 \mathrm{mg} \mathrm{dm}^{-3}$, aos 30 dias, com $\mathrm{pH}$ em torno de 7,5 (Figura 1). Já aos 60 dias (Figura 3), o menor teor de Cd extraído, cerca de $11,4 \mathrm{mg} \mathrm{dm}^{-3}$, resultou de $9978 \mathrm{mg} \mathrm{dm}^{-3}$ de silício $\mathrm{x}$ $90 \mathrm{mg} \mathrm{dm}^{-3}$ de fósforo, com $\mathrm{pH}$ em torno de 7,8 (Figura 1). Neste 


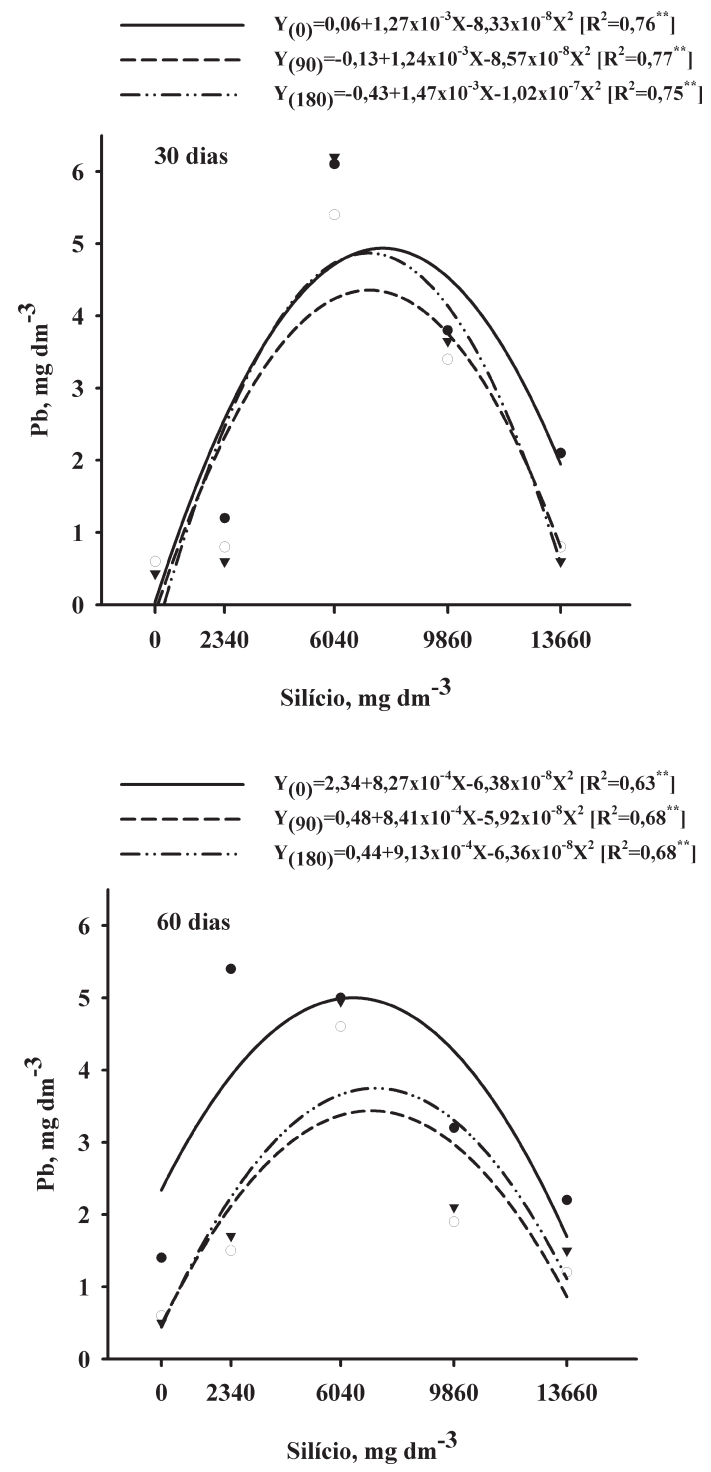

Figura 2. Teores de Pb extraídos pelo DTPA, em função das doses de silício e de fósforo $\left(\mathrm{mg} \mathrm{dm}^{-3}\right)$, em diferentes períodos de incubação

último caso, parece que houve precipitação do metal com o fosfato diácido, $\left(\mathrm{H}_{2} \mathrm{PO}_{4}^{-}\right)$, na forma $\mathrm{Cd}_{5} \mathrm{H}_{2}\left(\mathrm{PO}_{4}\right)_{4}{ }^{10}$. Já a dose $13660 \mathrm{mg} \mathrm{dm}{ }^{-3}$ combinada com $0,90,180$ e $360 \mathrm{mg} \mathrm{dm}^{-3}$ de fósforo, após 30 dias da aplicação, permitiu uma extração praticamente igual àquela do tratamento controle (zero de silício e zero de fósforo) e, às vezes, até inferior à do tratamento controle, aos 60 dias (Figura 3). Essa baixa eficiência do silício e do fósforo, à medida que aumentam os teores dos dois elementos no solo, parece relacionar-se com a precipitação do $\mathrm{Cd}$, como silicatos ou fosfatos.

Aos 30 e 60 dias (Figura 3), a maior extração de $\mathrm{Cd}$ ocorreu entre pH 4,6 e 5,9 (Figura 1), mostrando que, nesta faixa, o Cd possui alta mobilidade em solos, por ser fracamente adsorvido à matéria orgânica

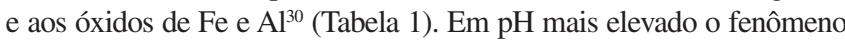
não ocorre, pois o mesmo tende a precipitar-se como fosfato de cádmio, diminuindo sua solubilidade. A dose $720 \mathrm{mg} \mathrm{dm}^{-3}$ de fósforo, aos $30 \mathrm{e}$ 60 dias (Figura 3), não permitiu ajuste matemático.

Teores de cobre extraídos pelo DTPA, em função das doses de silício e de fósforo

Os mínimos teores de cobre extraídos aos 30 e 60 dias (Figura

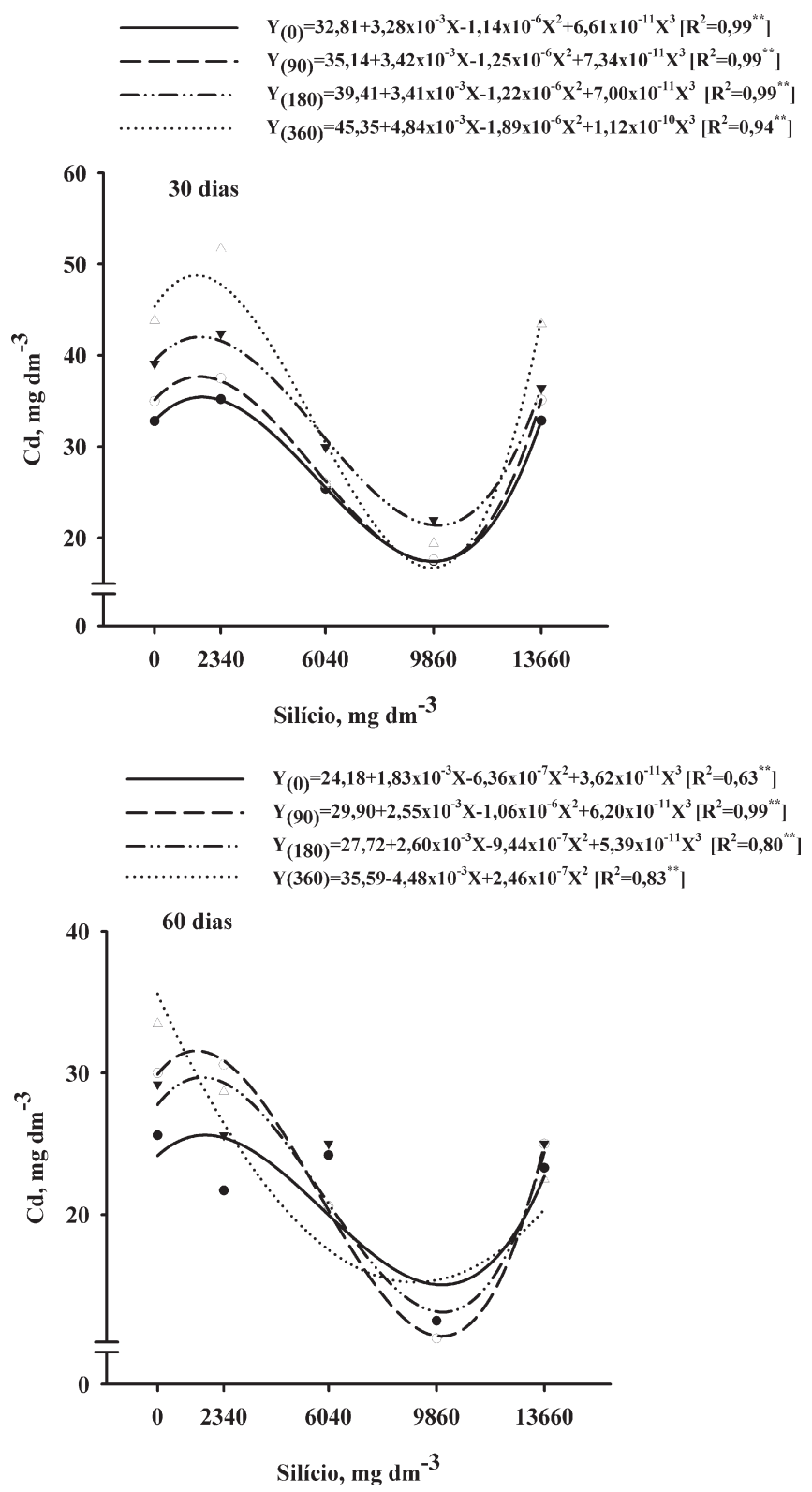

Figura 3. Teores de Cd extraídos pelo DTPA, em função das doses de silício e fósforo $\left(\mathrm{mg} \mathrm{dm}^{-3}\right)$, em diferentes períodos de incubação

4), cerca de 7 e $5,0 \mathrm{mg} \mathrm{dm}^{-3}$, respectivamente, ocorreram com 7682 mg dm${ }^{-3}$ de silício x $90 \mathrm{mg} \mathrm{dm}^{-3}$ de fósforo. Neste caso, também apareceram teores extraídos inferiores àqueles relativos a $0 \mathrm{mg} \mathrm{dm}^{-3}$ de fósforo, implicando na precipitação de fosfatos de cobre.

$\mathrm{Na}$ dose $13660 \mathrm{mg} \mathrm{dm}^{-3}$ de silício (Figura 4), a extração aos 30 dias foi inferior à do tratamento controle (zero de silício e zero de fósforo), sendo praticamente igual aos 60 dias. A dose $720 \mathrm{mg} \mathrm{dm}^{-3}$ de fósforo (Figura 4), combinada com as crescentes doses de silício, proporcionou teores de $\mathrm{Cu}$ superiores às demais em todas as épocas, nos menores valores de $\mathrm{pH}$ (Figuras 1). Isso sugere ter ocorrido saturação dos sítios de adsorção do solo (óxidos de Fe e Al) por silício e/ou fósforo, impedindo a formação de complexos de superfície entre os mesmos e o cobre, ou ainda, pela polimerização dos átomos de silício. Neste caso, o $\mathrm{Cu}^{+2}$ reage prontamente com os polímeros, complexando-os e garantindo sua estabilidade em solução?.

De modo geral, aos 30 e 60 dias (Figura 4) há uma relação inversa entre os teores de $\mathrm{Cu}$ extraídos pelo DTPA e os valores de 


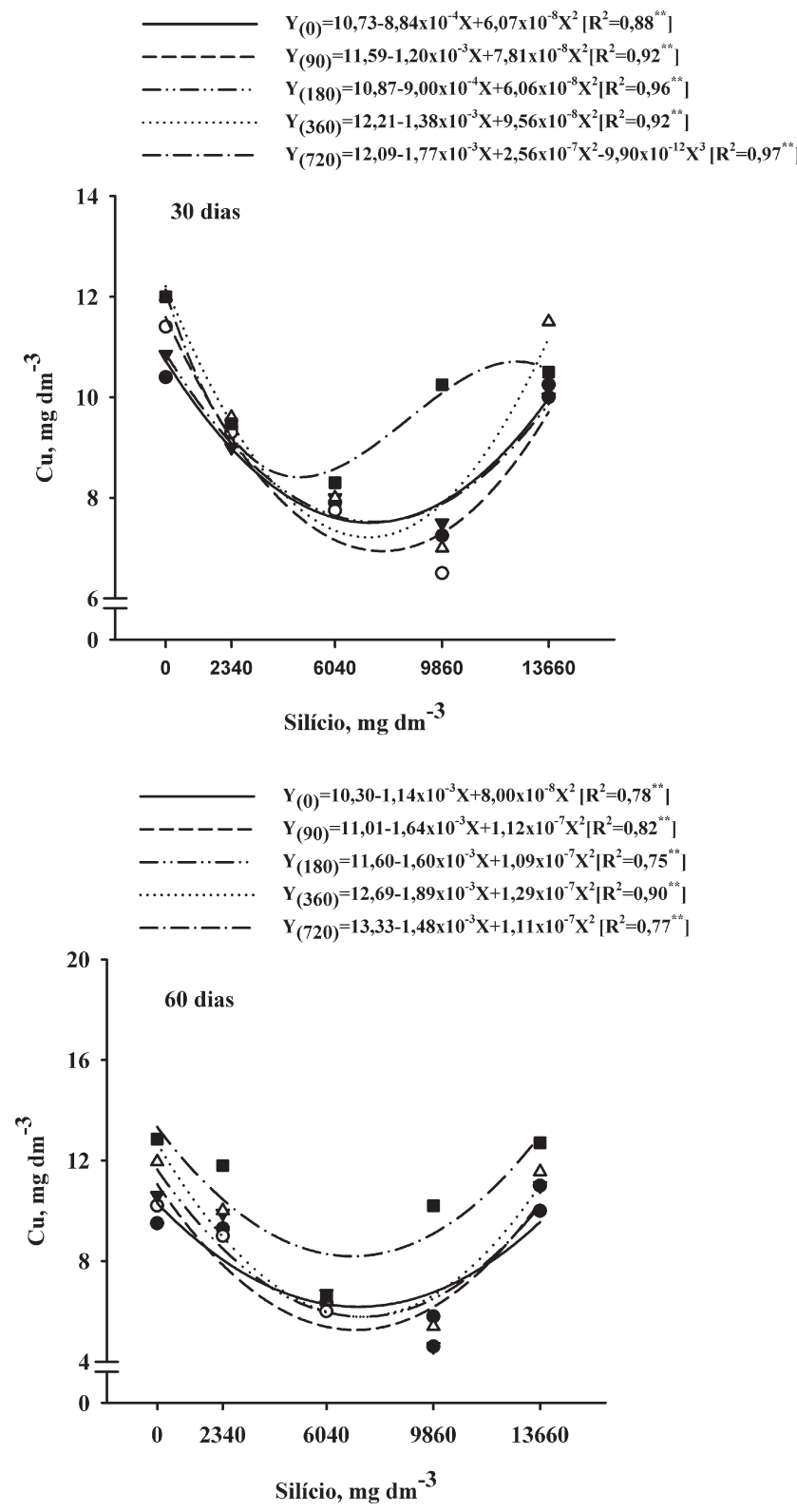

Figura 4. Teores de Cu extraídos pelo DTPA em função das doses de silício e fósforo $\left(\mathrm{mg} \mathrm{dm}^{-3}\right)$, em diferentes períodos de incubação

$\mathrm{pH}$ (Figura 1): quanto maior o $\mathrm{pH}$, menor foi o teor extraído. Isto pode ser constatado na dose máxima de silício, em que ocorreu precipitação do excesso de ânion silicato, diminuindo o $\mathrm{pH}$ e aumentando a disponibilidade do metal, cujo teor ficou praticamente igual ao tratamento controle. É possível que o ocorrido se deva à baixa disponibilidade do metal no solo com o aumento do $\mathrm{pH}$, já que o mesmo é fortemente adsorvido pela matéria orgânica e pelos óxidos de $\mathrm{Fe} \mathrm{Al}^{30}$ (Tabela 1), além de se precipitarem como fosfatos, $\left(\mathrm{Cu}_{3}(\mathrm{OH})_{3} \mathrm{PO}_{4}, \mathrm{CuNH}_{4} \mathrm{PO}_{4}\right.$ ou $\left.\mathrm{CuOHPO}_{4}\right)$, com a elevação do $\mathrm{pH}$, segundo Ayati e Madsen ${ }^{10}$.

\section{Teores de zinco extraídos pelo DTPA, em função das doses de} silício e de fósforo

Para o zinco, aos 30 dias (Figura 5), o teor mínimo extraído, cerca de $586 \mathrm{mg} \mathrm{dm}^{-3}$, foi obtido por $7534 \mathrm{mg} \mathrm{dm}^{-3}$ de silício $\mathrm{x}$ $0 \mathrm{mg} \mathrm{dm}^{-3}$ de fósforo, com $\mathrm{pH}$ em torno de 7,5 (Figura 1). Sugere-se que o $\mathrm{pH}$, muito mais que o fósforo, influiu na disponibilidade do $\mathrm{Zn}$

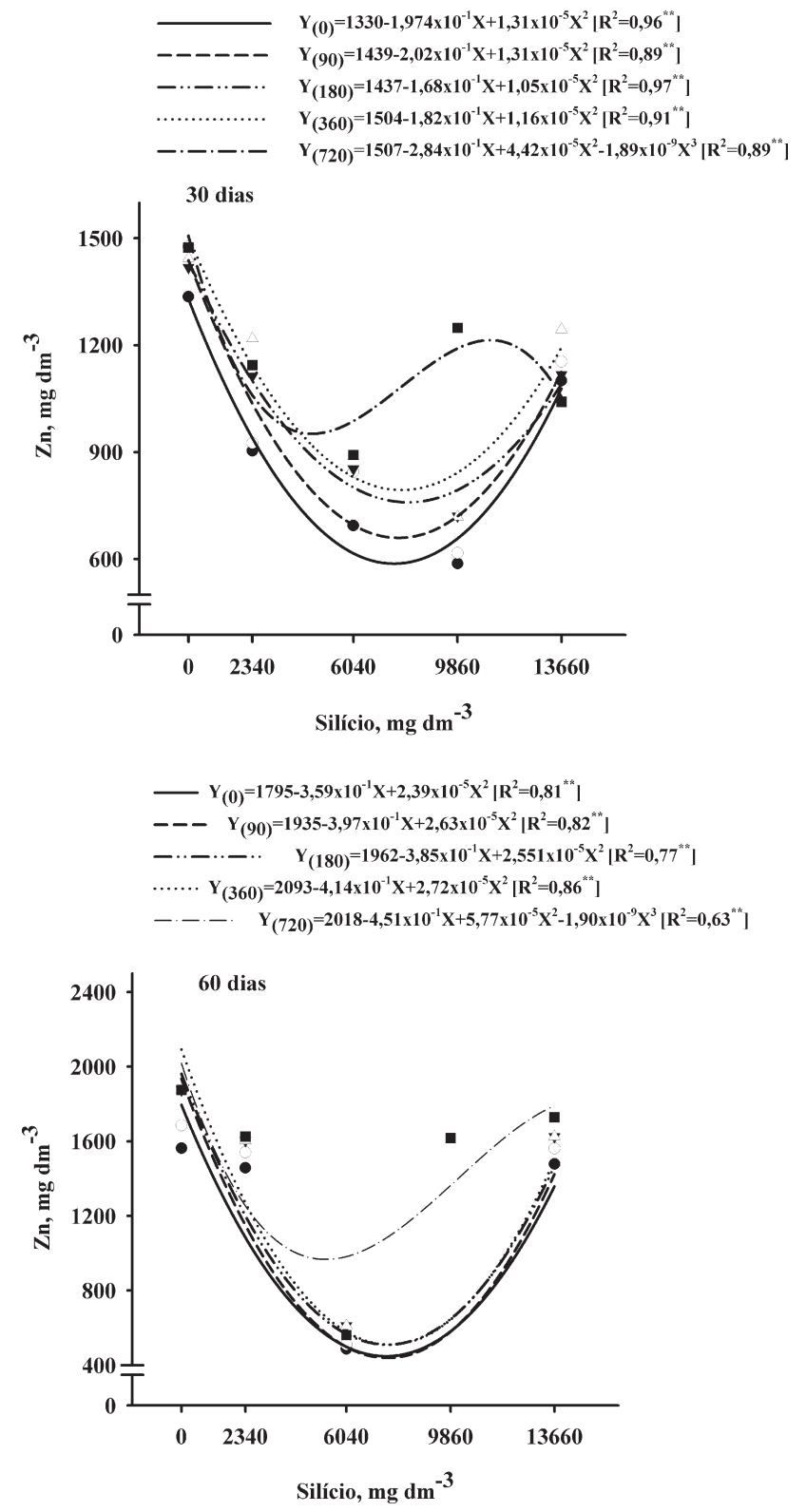

Figura 5. Teores de Zn extraídos pelo DTPA, em função das doses de silício e fósforo $\left(\mathrm{mg} \mathrm{dm}^{-3}\right)$, em diferentes períodos de incubação

extraído pelo DTPA, já que este possui alta mobilidade em solos, principalmente se estiver disponível para realizar trocas iônicas. Entretanto, em pH mais elevado, a possível adsorção a óxidos de $\mathrm{Fe}$ e $\mathrm{Al}$ e a complexação com a matéria orgânica (Tabela 1) podem ter contribuído para diminuir sua solubilidade ${ }^{29}$. Aos 60 dias (Figura 5), o mínimo extraído, cerca de $437 \mathrm{mg} \mathrm{dm}^{-3}$, referente à dose $7510 \mathrm{mg}$ $\mathrm{dm}^{-3}$ de silício x $90 \mathrm{mg} \mathrm{dm}^{-3}$ de fósforo é explicado pela possível precipitação do zinco como fosfato, $\mathrm{Zn}\left(\mathrm{H}_{2} \mathrm{PO}_{4}\right)_{2}$, imobilizando ainda mais o metal no solo. A dose $720 \mathrm{mg} \mathrm{dm}^{-3}$ de fósforo combinada com as crescentes doses de silício proporcionou teores de $\mathrm{Zn}$ superiores às demais em todas as épocas, nos menores valores de $\mathrm{pH}$ (Figura 1). Isto sugere ter ocorrido saturação dos sítios de adsorção do solo pelo silicato e/ou fósforo, a qual impede a formação de complexos de superfície entre os mesmos e o Zn, ou ainda, pela polimerização dos atomos de silício, que pode ser a provável causa dos elevados teores de $\mathrm{Zn}$ a $720 \mathrm{mg} \mathrm{dm}^{-3}$ de fósforo combinada com as crescentes doses de silício. Neste caso, o $\mathrm{Zn}^{+2}$ reage com os polímeros, complexando-os e garantindo sua estabilidade em solução?. 
Com a dose $13660 \mathrm{mg} \mathrm{dm}^{-3}$ de silício combinado com qualquer dose de fósforo, em todas as épocas (Figura 5), o teor de $\mathrm{Zn}$ diminuiu em relação ao tratamento controle, o que sugere ter ocorrido precipitação do metal como fosfato ou silicato.

Pelo fato do $\mathrm{Cd}, \mathrm{Cu}$ e $\mathrm{Zn}$ serem ácidos de Lewis (moderado) não necessitaram de $\mathrm{pH}$ elevado para que a molécula de DTPA liberasse os $\mathrm{H}^{+}$dos grupos carboxílicos e formasse quelatos estáveis do tipo Cd-DTPA, Cu-DTPA e Zn-DTPA $(\log \mathrm{K}=19,0 ; 21,0$; $18,8)^{28}$.

\section{CONCLUSÕES}

As doses crescentes de silício e fósforo reduziram os teores de $\mathrm{Cd}, \mathrm{Pb}, \mathrm{Cu}$ e $\mathrm{Zn}$ em solo contaminado.

Fósforo e silício foram mais eficientes em amenizar a poluição do solo por $\mathrm{Pb}$ e $\mathrm{Cu}$ do que por $\mathrm{Cd}$ e $\mathrm{Zn}$.

A ação do silício deveu-se ao poder alcalinizante do silicato de cálcio e a sua capacidade de formar silicatos insolúveis.

A amenização pelo fósforo decorreu da baixa solubilidade dos fosfatos de metais pesados.

O extrator DTPA, rotineiramente utilizado nas análises das disponibilidades de $\mathrm{Cu}, \mathrm{Zn}$, Fe e $\mathrm{Mn}$ para as plantas em solos agrícolas, foi eficiente na extração de metais pesados em solo contaminado.

\section{AGRADECIMENTOS}

À CAPES pela concessão de uma bolsa a L. A. Paim no curso de Mestrado em Agroquímica e Agrobioquímica do DQ da UFLA.

\section{REFERÊNCIAS}

1. Ribeiro, F. M. R.; Curi, N.; Siqueira, J. O.; Motta, P. E. F.; R. Bras. Ci. Solo 1999, 23, 453; Paim, L. A.; Carvalho, R.; Melo, W. C.; Neto, A. E. F.; Ciência Agrotecnologia 2003, 27, 780 .

2. Baird, C.; Química Ambiental, $2^{\mathrm{a}}$ ed., Bookman: Porto Alegre, 2003.

3. Chander, K.; Brookes, P. C.; Soil Biol. Biochem. 1993, 25, 1231.

4. Sheppard, S. C.; Gaudet, C.; Sheppard, M. I.; Cureton, P. M.; Wong, M. P.; Can. J. Soil Sci. 1992, 72, 359.
5. King, L. D. Em Soil Heavy Metal; Alvarez, V.; Fontes, L. E.; Fontes, M. P. F.; eds.; Viçosa, Sociedade Brasileira de Ciência do Solo, 1996, p. 823.

6. Vale, F. R.; Guedes, C. A. A.; Guilherme, L. R. G.; Manejo da Fertilidade do Solo, Faepe: Lavras, 1995.

7. Pierangeli, M. A. P.; Guilherme, L. R. G.; Curi, N.; Silva, M. L. N.; Oliveira, L. R.; Lima, J. M.; R. Bras. Ci. Solo 2001, 25, 279.

8. Shriver, D. F.; Química Inorgânica, $3^{\mathrm{a}}$ ed., Bookman: Porto Alegre, 2003.

9. Dietzel, M.; Geochim. Cosmochim. Acta 2000, 64, 3275.

10. Ayati, M.; Madsen, H. E. L.; J. Cryst. Growth 2001, 208, 579.

11. Carvalho, R.; Neto, A. E. F.; Curi, N.; Fernandes, L. A.; Oliveira, A. C. Jr.; Pesquisa Agropecuária Brasileira 2001, 36, 557.

12. Mantovani, J. R.; Cruz, M. C. P.; Ferreira, M. E.; Alves, W. L.; Pesquisa Agropecuária Brasileira 2004, 39, 371.

13. Pires, A. M. M.; Mattiazzo, M. E.; Berton, R. S.; Pesquisa Agropecuária Brasileira 2004, 39, 671 .

14. EMBRAPA - Empresa Brasileira de Pesquisa Agropecuária; Manual de Métodos de Análise de Solo, Centro Nacional de Pesquisa de Solos: Rio de Janeiro, 1997.

15. Vettori, L.; Métodos de Análise do Solo, Rio de Janeiro, 1969; Alvarez, V.; Fonseca, V. H.; R. Bras. Ci. Solo 1990, 14, 49.

16. Quaggio, J. A.; Raij, B. V.; Malavolta, E.; Commun. Soil Sci. Plant Anal. 1985, 16, 245.

17. Raij, B. V.; Quaggio, J. A.; Cantarella, H.; Análise Química do Solo para Fins de Fertilidade, 1987; Raij, B. V.; Commun. Soil Sci. Plant Anal. 1994, $25,799$.

18. Mehra, O. P.; Jackson, M. L.; Clays Clay Miner. 1960, 7, 317.

19. Inda, A. V. Jr.; Kämpf, N.; R. Bras. Ci. Solo 2003, 27, 1139.

20. Syers, J. K.; Browman, M. G.; Samille, G. W.; Corey, R. B.; Soil Sci. Soc. Am. J. 1973, 37, 358.

21. Freire, J. C.; Ribeiro, M. A. V.; Bahia, V. G.; Lopes, A. S.; Aquino, L. H.; R. Bras. Ci. Solo 1980, 4, 5 .

22. Roy, A. C.; Ali, M. V.; Fox, R. L.; Silva, J. A.; Symposium on Soil Fertility and Evaluation, 1971

23. Lindsay, W. L.; Norvell, W. A.; Soil Sci. Soc. Am. J. 1978, 42, 421.

24. Zonta, E. P.; Machado, A. A.; Manual do Sanest: Sistema de Análise Estatística para microcomputadores, UFP: Pelotas, 1991.

25. Huheey, J. E.; Keiter, E. A.; Keite, R. L.; Inorganic Chemistry, Principles of Structure and Reactivity, $4^{\mathrm{a}}$.ed., Harper Collins College Publisbers, 1993.

26. Hingston, F. J.; Posner, A. M.; Quirk, J. P.; J. Soil Sci. 1972, 23, 177.

27. Volkweiss, S. J.; Raij, B. V.; Simpósio Sobre Cerrado, Bases Para Utilização Agropecuária, 1977.

28. Blaedel, W. J.; Meloche, V. W.; Elementary Quantitative Analysis, $2^{\text {nd }}$ ed., Harper \& Row Publishers: New York, 1963.

29. Matos, A. T.; Fontes, M. P. F.; Costa, L. M.; Martinez, M. A.; Environ. Pollut. 2001, 111, 429 .

30. Mcbride, M. D.; Environmental Chemistry of Soils, New York: Oxford University, 1994. 